\title{
METODOLOGIAS ATIVAS NA DISCIPLINA DE URGÊNCIA E EMERGÊNCIA: CONTRIBUIÇÃO PARA FORMAÇÃO DO ENFERMEIRO A PARTIR DE UMA ANÁLISE BIBLIOGRÁFICA.
}

\section{ACTIVE METHODOLOGIES IN THE EMERGENCY AND URGENCY DISCIPLINE: CONTRIBUTION FOR NURSE TRAINING FROM A BIBLIOGRAPHIC ANALYSIS.}

Ana Carla Almeida Xavier ${ }^{1}$, Gislene de Jesus Cruz Sanches ${ }^{2}$, Kay Amparo Santos Duque ${ }^{2}$, Andressa Teixeira Santos Correia ${ }^{2}$, Ramon Evangelista Luz $^{3}$

Universidade Estadual do Sudoeste da Bahia ${ }^{1}$, UNIFTC $^{2}$, FAPEC $^{3}$

\section{Abstract}

The aim of this study is to analyze the contents in scientific articles about the process of nursing education and to identify the skills needed to work in hospital emergency units, highlighting the active methodologies as an innovative proposal. Systematic Review, in the period 2010-2017, the data searches were in the Scielo and Lilacs, from the keywords Nursing, Emergency, Students, Methodology. Corresponding to the results, we observed that the prevalence of the sample of the 12 publications was in 2015 with a sample of 5 articles, being $42 \%$ of the sample and 2014 being 4 articles referring to 33\%. The languages between English, Portuguese and Spanish, prevailing Portuguese and English being 42\% of the chosen sample. Nursing care in hospital emergency units requires from the nurse scientific knowledge creative and effective critical thinking. Thus, the active methodologies place the student as the protagonist of their learning, thus making them able to solve problems and situations inherent to the nursing function.

Keywords: Nursing, Ambulatory Care, Students, Methodology.
Resumo

Objetivo deste estudo é analisar os conteúdos em artigos científicos sobre processo de formação do enfermeiro e identificar as habilidades necessárias para atuação em unidades de emergência hospitalares, destacando as metodologias ativas como proposta inovadora. Revisão Sistemática, no período de 2010-2017.1, a busca de dados foi nas plataformas foram na Scielo e Lilacs, a partir dos descritores Enfermagem, Emergência, Estudantes, Metodologia. Correspondendo aos resultados, observamos que a prevalência da amostra das 12 publicações foi nos anos de 2015 com amostra de 5 artigos, sendo 42\% da amostra e 2014 sendo 4 artigos referindo 33\%. Os idiomas entre Inglês, português e Espanhol, prevalecendo o Português e Inglês sendo $42 \%$ da amostra escolhida. A assistência de enfermagem em unidades de emergências hospitalares requer do enfermeiro conhecimento científico pensamento crítico criativo e eficaz. Dessa, forma as metodologias ativas colocam o graduando como protagonista do seu aprendizado, tornando-os assim capazes de resolver problemas e situações inerentes à função da enfermagem.

Palavras Chave: Enfermagem, Emergência, Estudantes, Metodologia. 


\section{Introdução}

O Nas últimas décadas, em todo mundo, além de crescentes inovações tecnológicas vêm trazendo consigo o despertar para o mundo acadêmico. A busca pelo ensino superior, constituem um grande passo a ser alcançado e explorado pelos estudantes, onde para muitos a oportunidade de início da formação da carreira.

No Brasil, essa realidade não é diferente, o governo federal em 2004 criou o Programa Universidade para Todos (PROUNI) institucionalizado pela Lei no 11.096, em 13 de janeiro de 2005, onde enfatiza que a educação superior está fortemente conectada ao desenvolvimento econômico e social do País, seja enquanto formadora de recursos humanos altamente qualificados ou como peça imprescindível na produção científicotecnológica, elemento-chave da integração e formação da nação ${ }^{1}$.

No âmbito da saúde há uma crescente procura por cursos acadêmicos que capacitem os indivíduos para se tornarem atuantes no cuidar, estando de acordo com Ortega et al. ${ }^{2}$. Os avanços técnico-científicos enfrentados todos os dias na área da saúde, juntamente com as informações adquiridas pelo usuário, exige melhoria da qualidade assistencial recebida. Esta deve ser gerenciada através de ações técnicas e éticas dos profissionais de saúde, dependendo, além de tudo, daquilo que afeta a qualidade dos serviços prestados, tanto dos recursos materiais, quanto humanos.

A história da atuação da enfermagem no Brasil se estende dos tempos coloniais com as casas de misericórdia oriundas de Portugal, do Brasil Império, sendo a percussora Anna Justina Ferreira Nery, tendo à dedicação as ações de enfermagem um fator crucial. As universidades que ofertam o curso de enfermagem, instruem seus discentes uma dedicação ao conhecimento científico como fator norteador de um bom aprendizado, gerando assim, profissionais capazes de atuar de acordo com os requisitos do atual mercado de trabalho.

O curso de enfermagem deve garantir a formação de profissionais competentes, que prestam cuidados seguros e de qualidade, além de ativos e criativos, capazes de responder às demandas atuais e futuras de saúde, assim como adaptar-se à constante evolução do conhecimento e da tecnologia. Essa postura do profissional atual para o mercado de trabalho caracteriza-se justamente na proposta de capacitação do graduando através das metodologias ativas. ${ }^{3}$
Esse processo de adaptação se destaca na disciplina de emergências, aonde o aluno se depara com vítimas de incidentes domésticos, acidentes automobilísticos, diversos traumas, infartos e acidentes vasculares cerebrais ocasionados por maus hábitos de vida, sedentarismo, consumo exagerado de álcool dentre outros, onde sobrecarregam as emergências hospitalares. Diante do exposto o discente em campo de estágio deve ser adaptável e rápido, associando o conteúdo da matéria, executando frente ao atendimento ofertado.

O processo de aprendizagem requer do aluno sua capacidade e habilidade de demonstrar em situações práticas a assimilação e interpretação do conteúdo do conhecimento transmitido. A estratégia de ensino direciona o estudante, a através do conhecimento científico ministrado nas aulas, e o lado prático nos laboratórios a desenvolverem técnicas assistenciais ao cuidado. Também estimula associação de conteúdos já apresentados em outras disciplinas com as teorias específicas da urgência e emergência, gerando um raciocínio lógico para um bom atendimento em campo de práticas hospitalares.

A relevância dessa temática é de extrema importância porque, atualmente as emergências necessitam de profissionais capazes de atuação e também que tenham o perfil exigente pelo SUS englobando seus princípios e diretrizes. Esse processo se inicia através do período de graduação. Dessa maneira capacitar os acadêmicos através de metodologias ativas de ensino, resultará em profissionais preparados para o mercado de trabalho, que exige cada vez mais, profissionais criativos e proativos.

Entretanto, será que ocorre o resultado esperado, no desenvolvimento do discente frente a absorção do conhecimento e a atuação nos campos de estágios? Partindo desse pressuposto, emerge a inquietação com a seguinte questão norteadora: $O$ que trazem as produções científicas sobre o processo de formação do enfermeiro e quais são habilidades necessárias para atuação em unidades de urgência e emergência?

O objetivo dessa pesquisa é analisar as produções científicas sobre processo de formação do enfermeiro e identificar as habilidades necessárias para atuação em unidades de emergência. Destacando assim as metodologias ativas como proposta inovadora. 


\section{Metodologia}

A Revisão Sistemática de literatura é um método que tem como finalidade sintetizar resultados obtidos em pesquisas sobre um tema ou questão, de maneira sistemática, ordenada e abrangente. É denominada sistemática porque fornece informações mais amplas sobre um assunto/problema, constituindo, assim, um corpo de conhecimento, permitindo a inclusão simultânea de pesquisa quase-experimental e experimental, combinando dados de literatura teórica e empírica, proporcionando compreensão mais completa do tema de interesse ${ }^{5}$.

Essa apuração seguiu um processo de elaboração da Revisão Sistemática que percorre seis etapas, similares aos estágios de desenvolvimento de pesquisa, usual identificação do tema e seleção da hipótese ou questão de pesquisa; de critérios para inclusão e exclusão de estudos/amostragem ou busca na literatura; definição das informações a serem extraídas dos estudos selecionados/ categorização dos estudos; avaliação dos estudos incluídos; interpretação dos resultados; e apresentação da revisão/síntese do conhecimento ${ }^{5}$.

A busca pelos artigos partiu da temática e elaboração da questão de pesquisa já estabelecidos. O tema pesquisado trata sobre estratégias de ensino-aprendizagem no qual são discutidas a importância da utilização de Metodologias Ativas na disciplina de Urgência e Emergência na graduação de enfermagem.

Foram utilizados critérios de inclusão e exclusão para a obtenção do conteúdo científico, onde foi determinado por cinco fases. $\mathrm{Na}$ primeira fase foram estabelecidos quais os bancos de dados serão utilizados para a pesquisa bibliográfica que foram Scielo e Lilacs com artigos publicados nos últimos sete anos, considerando o início das publicações encontradas.

$\mathrm{Na}$ segunda fase foram instituídos os descritores da pesquisa. A busca nas bases de dados foi realizada utilizando os seguintes descritores (DeCS/MeSH) para cada base de dados diferencialmente, na Scielo: Emergência, Educação e Metodologia. Na Lilacs: Graduação, Enfermagem.

$\mathrm{Na}$ terceira fase foram estabelecidos os critérios de inclusão e exclusão para seleção dos artigos científicos. Critérios de inclusão: artigo completo, e disponível em periódicos indexados nas bases de dados virtuais e disponíveis nos idiomas: português, inglês e espanhol selecionados para a leitura; coniventes a temática. Ano de publicação, entre 2010 2017.1. Critérios de exclusão: Estudos em que o foco principal não era pertinente à temática, ou seja, publicações que não se referiam a enfermagem ou estudantes de enfermagem e metodologias, após a leitura do resumo. Artigos que se duplicavam na base de dados também foram excluídos, por serem produções duplicadas.

Quarta fase: a escolha dos artigos através da leitura de título, abstract e texto completo. A leitura dos títulos e objetivos geral constituiu o ponto de partida para a aplicação dos critérios de inclusão e exclusão. Na base de dados da Scielo, foram filtrados 79 artigos, após leitura exploratória, utilizou-se 08 artigos. Na base de dados da Lilacs foram filtrados 220 artigos científicos, aplicando descritores AND e após leitura exploratória, utilizou-se nove artigos. Excluíram-se os artigos duplicados e aqueles não relacionados ao tema. Também foi utilizado para alcançar objetivos esperados na pesquisa um Caderno de Atenção a Urgências e Emergências do Ministério da Saúde 2014, e Manual do Ministério da Educação - Universidade para todos.

Quinta fase: foi realizado um fichamento prévio dos 17 artigos, onde conclui-se que apenas 12 estavam aptos para serem classificados segundo as temáticas definidas. Identificou-se os artigos por letras, sendo A-B-C e numerou-se de acordo com a ordem de utilização a serem explorados. Na categoria A: publicações que nos davam definições simples como: o que é emergência, o que é necessário para trabalhar em emergências, processo de aprendizagem. A categoria B: publicações que discorrem sobre metodologias ativas e seus tipos, destacando assim, os três tipos de metodologias préestabelecidos para defesa. A categoria C: artigos que remetem a importância da utilização de novas metodologias de ensino e sua contribuição para o processo de formação de acadêmicos em cursos de saúde. A quinta fase caracterizou-se como essencial para obtenção dos resultados.

\section{Resultados e discussão}

Após a aplicação de todos os critérios de exclusão restaram para análise 12 artigos que abordavam a temática. O quadro abaixo apresenta a relação dos artigos selecionados para a amostra. 
Quadro 1: Distribuição das informações sobre os artigos científicos selecionados.

\begin{tabular}{|c|c|c|c|c|}
\hline $\begin{array}{l}\text { Ordem de } \\
\text { Utilização }\end{array}$ & Título & Objetivo & Ano & Periódico \\
\hline $\mathrm{N}^{\circ} 01$ & $\begin{array}{l}\text { Serviços de urgência e emergência: } \\
\text { quais os motivos que levam o } \\
\text { usuário aos pronto-atendimentos? }\end{array}$ & $\begin{array}{l}\text { Analisar os motivos da procura dos } \\
\text { usuários pelos serviços de um Pronto- } \\
\text { Atendimento no município de Santa } \\
\text { Maria, RS }\end{array}$ & 2015 & $\begin{array}{l}\text { Saúde (Santa Maria), Santa } \\
\text { Maria. }\end{array}$ \\
\hline $\mathrm{N}^{\circ} 02$ & $\begin{array}{l}\text { Desafios para a gerência do cuidado } \\
\text { em emergência na perspectiva de } \\
\text { enfermeiros }\end{array}$ & $\begin{array}{l}\text { Analisar os desafios para a gerência do } \\
\text { cuidado em um serviço hospitalar de } \\
\text { emergência, com base na perspectiva } \\
\text { de enfermeiros. }\end{array}$ & 2013 & $\begin{array}{l}\text { Acta Paulista de } \\
\text { Enfermagem. }\end{array}$ \\
\hline $\mathrm{N}^{\circ} 03$ & $\begin{array}{l}\text { Estratégias de avaliação da } \\
\text { aprendizagem aplicadas no ensino } \\
\text { de graduação em enfermagem no } \\
\text { Brasil. }\end{array}$ & $\begin{array}{l}\text { Identificar a produção científica e as } \\
\text { estratégias utilizadas na avaliação da } \\
\text { aprendizagem no ensino superior de } \\
\text { enfermagem no Brasil. }\end{array}$ & 2015 & $\begin{array}{l}\text { Revista Iberoamericana de } \\
\text { Educación e Investigación } \\
\text { en enfermeria. }\end{array}$ \\
\hline $\mathrm{N}^{\circ} 04$ & $\begin{array}{l}\text { Metodologias Ativas do que } \\
\text { estamos falando? Base conceitual e } \\
\text { relato de pesquisa em Andamento. }\end{array}$ & $\begin{array}{l}\text { Apresentar os principais conceitos, } \\
\text { ferramentas e métodos das } \\
\text { denominadas Metodologias Ativas e } \\
\text { aplicação das mesmas. }\end{array}$ & 2014 & $\begin{array}{l}\text { IX SIMPED - Simpósio } \\
\text { Pedagógico e Pesquisas em } \\
\text { Educação. }\end{array}$ \\
\hline $\mathrm{N}^{\circ} 05$ & $\begin{array}{l}\text { Analisando as metodologias ativas } \\
\text { na formação dos profissionais de } \\
\text { saúde: uma revisão sistemática. }\end{array}$ & $\begin{array}{l}\text { Analisar a produção cientifica que trata } \\
\text { das metodologias ativas na graduação. }\end{array}$ & 2014 & S A N A R E, Sobral. \\
\hline $\mathrm{N}^{\circ} 06$ & $\begin{array}{l}\text { Metodologias ativas na promoção } \\
\text { da formação crítica do estudante: } 0 \\
\text { uso das metodologias ativas como } \\
\text { recurso didático na formação crítica } \\
\text { do estudante do ensino superior. }\end{array}$ & $\begin{array}{l}\text { Apresentar metodologias ativas de } \\
\text { ensino-aprendizagem que sirvam como } \\
\text { recurso didático base para formação } \\
\text { crítica e reflexiva, e possam levar uma } \\
\text { reflexão construtivista da atuação do } \\
\text { docente em sala de aula. }\end{array}$ & 2014 & Cairu em Revista. \\
\hline $\mathrm{N}^{\circ} 07$ & $\begin{array}{l}\text { Estratégias } \text { baseadas } \\
\text { metodologias ativas no ensino } \\
\text { aprendizagem de primeiros } \\
\text { socorros: relato de experiência. }\end{array}$ & $\begin{array}{l}\text { Descrever a experiência de aplicação de } \\
\text { estratégias de metodologias ativas } \\
\text { durante a oficina em saúde de primeiros } \\
\text { socorros. }\end{array}$ & 2017 & $\begin{array}{l}\text { Revitas Enfermagem UFPE } \\
\text { on line. }\end{array}$ \\
\hline $\mathrm{N}^{\circ} 08$ & $\begin{array}{l}\text { Primeira prática curricular } \\
\text { hospitalar de estudantes de } \\
\text { enfermagem descrita em fórum } \\
\text { oline. }\end{array}$ & $\begin{array}{l}\text { Conhecer as vivências dos estudantes } \\
\text { de um curso de graduação em } \\
\text { enfermagem, na primeira prática } \\
\text { curricular hospitalar na área do cuidado } \\
\text { adulto, por meio de um fórum oline. }\end{array}$ & 2013 & Ciência, Cuidado e Saúde. \\
\hline$N^{\circ} 09$ & $\begin{array}{l}\text { Avaliação da qualidade do processo } \\
\text { de ensino-aprendizagem no curso } \\
\text { de graduação em enfermagem. }\end{array}$ & $\begin{array}{l}\text { Identificar os aspectos de melhoria da } \\
\text { qualidade do processo ensino- } \\
\text { aprendizagem através da análise de } \\
\text { ferramentas que avaliam a aquisição de } \\
\text { competências pelos alunos do curso de } \\
\text { enfermagem. }\end{array}$ & 2015 & $\begin{array}{l}\text { Revista Latino-Americana } \\
\text { de Enfermagem. }\end{array}$ \\
\hline$N^{\circ} 10$ & $\begin{array}{l}\text { Processo de formação crítico- } \\
\text { criativo: percepção dos formandos } \\
\text { de enfermagem. }\end{array}$ & $\begin{array}{l}\text { Compreender como os formandos de } \\
\text { graduação em enfermagem de uma } \\
\text { Universidade Pública do Rio Grande do } \\
\text { Sul do Brasil percebem o seu processo } \\
\text { de formação para a construção do } \\
\text { profissional critico criativo. }\end{array}$ & 2015 & $\begin{array}{l}\text { Revista Iberoamericana de } \\
\text { Educación e Investigación } \\
\text { en enfermeria. }\end{array}$ \\
\hline$N^{\circ} 11$ & $\begin{array}{l}\text { Percepção de estudantes de } \\
\text { enfermagem sobre o processo de } \\
\text { aprendizagem em ambientes } \\
\text { hospitalares. }\end{array}$ & $\begin{array}{l}\text { Identificar como os estudantes de } \\
\text { enfermagem perceberam e vivenciaram } \\
\text { o processo de aprendizagem durante } \\
\text { práticas curriculares realizadas em } \\
\text { ambiente hospitalar. }\end{array}$ & 2014 & $\begin{array}{l}\text { Revista Gaúcha } \\
\text { Enfermagem. }\end{array}$ \\
\hline$N^{\circ} 12$ & $\begin{array}{l}\text { Fatores preditores e associados a } \\
\text { satisfação dos estudantes de } \\
\text { enfermagem. }\end{array}$ & $\begin{array}{l}\text { Identificar os preditores e fatores } \\
\text { associados a satisfação dos estudantes } \\
\text { de enfermagem com as atividades de } \\
\text { currículo e ensino, interação } \\
\text { sócio/profissional e ambiente de } \\
\text { aprendizagem do curso de graduação. }\end{array}$ & 2015 & $\begin{array}{l}\text { Acta Paulista } \\
\text { Enfermagem. }\end{array}$ \\
\hline
\end{tabular}

Fonte: Dados da pesquisa 
No que se refere ao ano em que foram publicados os artigos, constatou-se que houve destaque no ano de 2015 com $42 \%$, com amostra de 5 artigos, em segundo lugar o ano de 2014 com 4 artigos sendo equivalente a $33 \%$, os anos menos publicados foram 2013 com 2 artigos sendo $17 \%$ e 2017 com apenas $1 \%$ até a presente busca pelos conteúdos. Nos anos de 2010, 2012 e 2016 os artigos apurados forem utilizados na introdução desses artigos.

Em relação ao idioma, segundo os critérios de inclusão, foram encontrados artigos nos idiomas, Português, Inglês e Espanhol. Contudo, haviam artigos que estavam disponíveis em dois ou até mesmo dentro desses três idiomas, somando o total 12 artigos correspondendo a $100 \%$. A prevalência fica evidente nos idiomas, Português e Inglês sendo $42 \%$ da amostra escolhida. Abaixo segue os artigos ordenados conforme o idioma (Tabela 2)

Quanto aos países que publicaram sobre o tema, apenas foram no Brasil e Espanha. Havendo a prevalência de revistas brasileiras representando $67 \%$ (8 revistas) e revistas espanholas com 33\% (4 revistas), destacando assim que a temática exposta se aplica a graduandos de enfermagem no Brasil.

A análise dos dados apresentados acima, coletados nos artigos possibilitou a classificação das publicações em três categorias temáticas, sendo A, B, C destrinchadas na quinta fase do processo metodológico. Primeira categoria temática - A: remete as unidades de urgências e emergências hospitalares, a atuação do enfermeiro e desenvolvimento de habilidades do discente. Corresponde a 3 artigos científicos (25\%) dessa revisão de literatura sistemática.

o Sistema único de Saúde através de suas diretrizes visa à integralidade na igualdade da assistência, organiza seu atendimento através de três níveis de atenção à saúde. Primeiro nível de atenção à saúde são conhecidas com Unidades Básicas de Saúde, agem promovendo políticas de saúde com a comunidade, prevenindo doenças e cuidando do bem estar. ${ }^{17}$

O segundo nível é atenção hospitalar, onde as urgências e emergências estão inseridas, sendo atendimento de alta complexidade. Freire et al. ${ }^{6}$ caracterizam 0 atendimento em emergências como a ocorrência imprevista de agravo à saúde com ou sem risco potencial de morte, além da constatação médica de condições de agravo à saúde que impliquem em risco iminente de morte. E o terceiro nível são hospitais de grande porte, são ofertados serviços de altas especialidades como, por exemplo, neurocirurgia e oncologia.

A portaria № 354 de 10 de março de 20147 define como Emergência a constatação médica de condições de agravo à saúde que impliquem sofrimento intenso ou risco iminente de morte, exigindo, portanto, tratamento médico imediato; e Urgência a ocorrência imprevista de agravo à saúde com ou sem risco potencial a vida, cujo portador necessita de assistência médica imediata. Podem funcionar como um serviço de saúde independente ou inserido em um estabelecimento com internação com maior capacidade de resolução.

Os estudos 1,2,3 mostram que o papel do enfermeiro é crucial para o bom andamento das emergências clínicas. Santos et al. ${ }^{8}$ explicam que na atuação dos enfermeiros na gerência do cuidado em um serviço de emergência, destacase a necessidade da busca constante pelo desenvolvimento de melhores estratégias que Ihes permitam superar os desafios impostos por um ambiente de trabalho marcado pela procura constante por atendimento.

Esses desafios caracterizam-se por superlotação, manutenção de qualidade do cuidado, gerenciamento das ações e priorização dos cuidados aos mais graves, disponibilidade e qualidade dos recursos materiais e objetivos organizacionais da equipe de enfermagem. Para a superação dos desafios, mais uma vez, Santos et al. ${ }^{8}$ discorrem que os enfermeiros de unidades de emergência devem aliar controle do tempo à fundamentação teórica, ao discernimento, à iniciativa, à maturidade e à estabilidade emocional e à capacidade de liderança, o que requer o desenvolvimento de habilidades como comunicação, relacionamento interpessoal e tomada de decisão.

O desenvolvimento das habilidades se faz necessário desde o processo de graduação dos acadêmicos de enfermagem, através das aulas e as práticas hospitalares onde o aluno pode comprovar nas suas vivências com o que se diz nas literaturas cientificas. Oliveira et al. ${ }^{4}$ apontam que o processo de aprendizagem requer do aluno sua capacidade e habilidade de demonstrar em situações práticas a assimilação e interpretação do conteúdo do conhecimento transmitido.

As estratégias que são mais utilizadas na transmissão do conhecimento que vem sendo utilizadas pelos docentes nos cursos de saúde, são estas convencionais onde o professor para trabalhar os conteúdos, como recursos pedagógicos, se apoia no livro didático, no giz, na lousa; sendo assim o principal mediador do processo ensino aprendizagem, restando ao 
aluno a automatização e memorização dos conteúdos ${ }^{4}$.

Porém, o objetivo da graduação é possibilitar a aprendizagem para que o aluno consiga aplicar - conteúdo nas suas vivências trabalhistas futuras, como relacionar teoria e prática nas disciplinas de urgências e emergências, e o ensino baseado em competências, trazendo uma postura ativa do aluno que o possibilita desenvolver a articulação e aplicação do saber, sendo evidenciado nos ensinos atuais, como as metodologias ativas.

Condizente assim com Oliveira et al. ${ }^{4}$ defendem que a avaliação do conhecimento também precisa estar condizente ao novo modelo de ensino que surge, o que gerou um estímulo aos educadores para propor novas formas de avaliação por meio de metodologias ativas que reconheçam o aluno como sujeito ativo da aprendizagem e o educador como facilitador desse processo.

A segunda categoria temática - B referese às publicações que tratam sobre as metodologias ativas, o seu conceito, os tipos. Porém, dos sete tipos que as publicações trazem, é explorado apenas três, porque se adequam melhor a temática exposta. Correspondem a 4 artigos (33\%) da amostra para o presente estudo.

As metodologias ativas educam o aluno para a autonomia, são metodologias inovadoras que através da pesquisa, trabalho em grupos, ajudam a descoberta e aprofundamento dos conhecimentos. São utilizadas como sistema educacional de graduação desde década de 60 , nos EUA e Canadá nos cursos de medicina, propondo assimilação e compreensão dos saberes.

Borges e Alencar ${ }^{9}$ dizem que se podem entender as metodologias ativas como formas de desenvolver o processo do aprender, na busca de conduzir a formação crítica de futuros profissionais nas mais diversas áreas. A utilização favorecerem a autonomia do educando, despertando a curiosidade, estimulando tomadas de decisões individuais e coletivas, advindos das atividades essenciais da prática social e em contextos do estudante.

As metodologias ativas buscam favorecer a motivação autônoma e tem o potencial de despertar a curiosidade, à medida que os alunos se inserem na teorização e trazem elementos novos, ainda não considerados nas aulas ou na própria perspectiva do professor ${ }^{10}$.

São denominadas ativas porque não ocorre a limitação do conhecimento. Também não possuem o papel de exclusão do preceptor em sala de aula. Ao contrário, encaram os professores como facilitadores, mediadores, orientadores do conhecimento. Apenas as fontes de conteúdos são oriundas de várias estratégias e não apenas das aulas expositivas, facilitando o processo de absorção do conhecimento e procurando a reorganização da teoria com a prática.

Xavier et al. ${ }^{11}$ discorrem sobre o papel do professor educador, dizendo que é através de saberes acumulados que o aluno se torna responsável e corresponsável pelo seu processo de aprender, o que leva o professor a exercer um papel apenas de mediador e coadjuvante, estimulando um aluno crítico e reflexivo.

Borges e Alencar ${ }^{9}$ ainda complementam afirmando que é fundamental que o professor participe do processo de repensar e construção do conhecimento, na qual a mediação e a interação são os pressupostos essenciais para que ocorra aprendizagem.

Os estudos 4, 5,6,7apontam também que as metodologias ativas têm o potencial de aproximação entre a realidade com a prática, familiarizando assim futuros ambientes de trabalho para os graduandos.

A implementação de práticas pedagógicas ocorre na tentativa de se aproximar da realidade social. Visto que a graduação dura alguns anos e o papel do profissional e seus conhecimentos têm uma duração maior e necessitam de mais autonomia para aprender a aprender com competência ética, raciocínio crítico, responsabilidade e sensibilidade ${ }^{11}$.

Diante de inúmeras evoluções ocorridas no mundo constantemente, no que se refere a educação não poderia ser diferente. As inovadoras metodologias chegam para transformar o aluno, mostrar a sua capacidade e buscar explorá-la da maneira que mais se adequa a seu perfil de aprendizagem. Dessa forma, se tem as diversidades de metodologias ativas, porém para cada uma é singular em aplicá-la.

Conforme cita Rocha e Lemos ${ }^{10}$, ao terem o professor como agente facilitador do processo de aprendizagem, têm os alunos "puxando" o ensino conforme suas necessidades, interesses, preferências e ritmo. Caso não haja a devida assimilação do conhecimento pelo imediatamente, será gerada uma "demanda" por intervenção do professor na medida e forma requerida pela carência específica apontada.

Algumas das metodologias mais destacadas pelos artigos selecionados são Aprendizagens Baseadas em Problemas (PBL), Métodos de caso e Simulações. Essas trabalham tendo base a problematização através de 
conteúdos programáticos, proporcionando o desenvolvimento do ensinar e aprender, gerando assim o pensamento analítico.

Aprendizagem Baseada em Problemas PBL é um método de aprendizagem que cria uma necessidade de resolver um problema não completamente estruturado, a exemplo do que poderia ocorrer fora da sala de aula. Durante o processo, os alunos constroem o conhecimento do conteúdo e desenvolvem habilidades de resolução de problemas bem como as competências de aprendizagem autodirigida ${ }^{10}$.

Uma metodologia inovadora que a partir das resoluções de problemas, faz com que o graduando absorva o conhecimento sobre os conceitos estudados de forma criativa e simples, porém aprofundada, o que o levará a aplicá-la futuramente. O problema direciona e motiva a aprendizagem de forma autodirigida. Gera dúvidas e proporciona à descoberta, a reflexão, a experimentação e permitem aos docentes a apresentação dos conteúdos programáticos por meio de problemas ou questionamentos ${ }^{11}$.

Rocha e Lemos $^{10}$ discorrem sobre as etapas de aplicação da PBL: (1) os alunos, em grupos de cinco a oito, começam a aprender, abordando simulações do problema não estruturado, (2) o conteúdo e as habilidades a serem aprendidas são organizados em torno de problemas, (3) os estudantes coletam informações e dividem seu aprendizado com o grupo; é auto reflexivo, de tal forma que os alunos monitoram sua compreensão e aprendem a ajustar as estratégias para a aprendizagem, (4) professores são facilitadores que apoiam e modelam os processos de raciocínio, facilitam processos grupais e dinâmicos interpessoais, sondam o conhecimento dos alunos e nunca inserem conteúdo ou fornecem respostas diretas às perguntas e; (5) no final do período de aprendizado (geralmente uma semana), os estudantes resumem e integram seus aprendizados.

Os métodos de casos atuam como facilitadores para que os alunos já com seus conhecimentos prévios, venham a estabelecer conexões sobre o caso de uma determinada patologia com o novo conteúdo estudado. Dessa forma despertará o raciocínio crítico, habilidades de comunicação e percepção da necessidade de aprender com a vida ${ }^{11}$.

Estimulam os alunos a pensarem e descobrirem, de forma ativa e não receptiva, por meio de perguntas e respostas que levem a reflexões relevantes: para tanto, o caso estudado apresenta um dilema, no qual os alunos testam suas habilidades técnicas e julgamentos. Ocorre a apresentação dos dilemas reais, onde decisões devem ser tomadas e consequências enfrentadas ${ }^{10}$.

Para ser aplicada, essa metodologia percorre três passos como é descrita por Rocha e Lemos10 onde: (1) ocorre a preparação individual, na qual o aluno ler o caso, estuda as fontes teóricas indicadas e prepara-se para a discussão; (2) o debate em pequenos grupos, ocorre a comparação das reflexões e respostas com as dos demais colegas, experiências e percepções: busca-se, nesse estágio, ampliar a visão e chegar a diferentes conclusões e; (3) discussão em sala de aula, em que cada aluno, na plenária, é responsável pelas suas ideias e conclusões, que devem ser defendidas, conduzida pelo professor por meio de um processo de questionamento crítico preparado por ele.

A simulação tem se destacado amplamente como metodologia ativa no ensino em saúde dentro da perspectiva interdisciplinar, nos cursos da área da saúde e na enfermagem. Promove a aprendizagem experiencial, a reflexão crítica, centrada no aluno e com apoio de um professor em ambiente seguro ${ }^{12}$.

É um instrumento para auxiliar e complementar a aula expositiva fornecendo oportunidades de participação interativa através de demonstrações. Incentiva e orienta o processo de descoberta do aluno, proporcionando-lhe um ambiente divertido e atraente no qual poderá fazer perguntas e ter feedback para descobrir a resposta. Contribui para melhorar a atenção, leva uma aprendizagem relativamente rápida e é muito eficaz em assuntos difíceis ${ }^{10}$.

Rosa et al. ${ }^{12}$ levam-nos a entender que os estudos são realizados em pequenos grupos, onde é exposta uma situação problema para após uma leitura e discussão de casos clínicos elaborados pelo professor, os integrantes dos grupos planejem uma dramatização proposta, onde cada grupo demonstrará como atuaria em situações específicas e como realizar atendimento ao paciente diante dos seus conhecimentos adquiridos em aulas expositivas.

A simulação é uma metodologia educativa que contempla as necessidades de aprendizagens do aluno associando essas duas vertentes do conhecimento, teoria e prática, uma vez que seu objetivo está centrado no aluno e não no paciente, como ocorre no contexto clínico $^{12}$.

Contribui assim, para que haja um treinamento e participação consciente de técnicas e raciocínio lógico, construção do 
conhecimento e profissional crítica, ética e reflexiva sem por em risco a vida de um paciente, permitindo retornar quantas vezes for necessário diante de erros.

Terceira categoria temática-C: refere-se às publicações que abordam sobre o processo de formação, estágios curriculares hospitalares, preditores do bom desempenho e aproveitamento dessas práticas. Finalizam as publicações fichadas, sendo 5( 42\%) dos artigos.

O desafio da educação em enfermagem é fazer uso dos melhores resultados da investigação clínica e educacional como base no ensino a fim de garantir tanto a qualidade do processo de ensino-aprendizagem como a qualidade do atendimento que será prestado pelos futuros profissionais ${ }^{3}$.

A qualidade do atendimento é gerada através do processo de aquisição do conhecimento e o momento em que o graduando passa a executá-la através das práticas curriculares, tendo o professor como mediador e facilitador das atividades técnicas. Alves e $\operatorname{Cogo}^{13}$ mostram que a interação entre as atividades teóricas e práticas apoiadas por diferentes métodos de ensino, devem promover a inserção do estudante de enfermagem no contexto das práticas de saúde.

A técnica é um fator somador de prestar assistência nos estágios hospitalares curriculares. Esse fator aliado ao conhecimento se torna essencial, e quando agregamos essas duas vertentes, sempre discutindo e analisando a técnica prestada se torna uma assistência segura para o paciente.

O início do estudante no ambiente hospitalar envolve questões complexas, como as duras tecnologias, o processo saúde e adoecimento, as políticas de saúde, a interação com os demais participantes, associados a insegurança, a incerteza e a ansiedade do estudante frente a uma experiência desconhecida, fatores geradores de estresse ${ }^{13}$.

O sucesso de um bom estágio nas emergências hospitalares depende do grau de satisfação que os graduandos sentem. Hirsch et al. ${ }^{14}$ relatam que a satisfação do indivíduo é uma consequência não apenas do quanto ele recebe do ambiente, mas também da posição que ele ocupa em relação ao seu nível idealização.

Dessa forma, os estudos mostram que o uso de metodologias adequadas, didática atualizada, distribuição dos conteúdos curriculares e consistência das disciplinas foram percebidas como os maiores promotores da satisfação ou insatisfação acadêmica. Portanto, o processo de ensino e aprendizagem requer práticas pedagógicas voltadas a aprendizagem significativas, as metodologias problematizadoras que estimulem o educando a buscar a sua autonomia e transformar a sociedade ${ }^{14,15}$.

Os benefícios que os estudos apontam sobre as metodologias inovadoras se adequam perfeitamente nas aulas em sala, antes dos graduandos irem às práticas hospitalares. Essas buscam a aproximação da realidade, a superação dos desafios e a segurança na tomada de decisão e aplicação das técnicas de enfermagem.

Hirsch et al. ${ }^{14}$ destacam que são atividades que estimulam a participação ativa dos estudantes na resolução de problemas, permitem que esses desenvolvam responsabilidades e a iniciativa, aumente a autonomia, controle, independência e segurança.

Pensando na assimilação rápida de sinais e sintomas pelos pacientes apresentados nas emergências, como por exemplo em múltiplos traumas, acidentes por arma branca, uso do laboratório de simulação, contribuirá para que o graduando consiga desenvolver e praticar habilidades que poderá se deparar futuramente, aplicando-as assim com segurança.

A aquisição de competências ocorre através de uma sequência de aprendizagem que permite a aquisição de conhecimentos durante as aulas de conteúdo teórico, aquisição das habilidades relacionadas a laboratórios de simulação e salas de simulações ${ }^{3}$.

Alves e Cogo $^{13}$ defendem que o diálogo está diretamente relacionado a capacidade de refletir sobre conhecimentos e processo de cuidar, ou seja, nesse momento o estudante age com responsabilidade, avaliando e modificando sua prática, capacitando o estudante a exercer sua profissão com maior qualificação e respeito ao usuário.

Nesse contexto, os estudos de casos são eficazes na avaliação do cuidado prestado ao paciente, na sua possível modificação e sinalização da terapêutica como também no progresso ou regresso da patologia destacada, por exemplo, as pneumonias respiratórias associadas à ventilação mecânica.

Aprendizagem baseada em problemas resulta de forma clássica da união do saber teórico com o prático. Ela aguça a curiosidade e o raciocínio lógico fazendo o aluno a desenvolver soluções a partir do problema encontrado, resultando em outro problema. Como por exemplo, uma cardiopatia congênita ou subsequente à outra patologia.

Ela faz essa união porque o aluno é levado a busca do saber e também como aplicálo na problemática estabelecida. Winters e Do 
Prado $^{15}$ ressaltam que esse processo de formação voltado a consciência crítica e a busca do conhecimento faz com que o educando reflita sobre o mundo e consiga transformá-lo. Essa transformação ocorre quando há apropriação de saberes para desenvolver o pensamento crítico.

As metodologias inovadoras na disciplina de urgências e emergências buscam justamente contribuir para que alunos tenham uma postura ativa e criativa, repercutindo positivamente na assistência prestada, ocorrendo a união da teoria e prática de forma igual e somatizada.

Essa equivalência resulta segundo Hirsch et al. $^{14}$ em similaridade dos conteúdos ministrados com a realidade prática e a potencialidade do currículo em promover uma formação condizente com as necessidades do mercado, contribuindo para o reforço da identidade profissional através do aumento das experiências e conhecimentos clínicos.

O educando crítico e criativo em Enfermagem é aquele que é capaz de inovar, ir além dos limites da imaginação, é capaz de observar um cuidado ou uma ação do cuidado e intervir de forma adequada com embasamento científico, não apenas ficar olhando, sem resposta. Ele é capaz de discutir a ação, refletir sobre esse cuidado e ter uma reação, ele procura transformar e mudar a sua realidade ${ }^{15}$.

\section{Conclusão}

O mercado de trabalho para enfermagem vem continuamente exigindo profissionais recém-formados com habilidades de gerência do serviço e paciente, uma assistência baseada na literatura científica, autonomia e agilidade para se obter qualidade na assistência. Ultrapassando dessa forma a ideia da caridade ou da enfermagem por amor, esse sentimento que é necessário em todas as profissões fica em segundo plano na sua atuação.

Diante do que foi exposto nessa Revisão Sistemática, fica evidente que o processo de aprendizagem na disciplina de urgência e emergência requer além de aulas expositivas dialogadas. O graduando precisa ser preparado a resolver problemas e situações inerentes a função da enfermagem, tendo a capacidade de detectar tais problemas e encontrar soluções eficazes e ágeis.

As Diretrizes Curriculares Nacionais da Graduação em Enfermagem nos mostram que o perfil que vem se construindo sobre o graduando desde o primeiro semestre é voltado para a formação humanista, crítica e reflexiva com base no rigor científico e intelectual e pautado em princípios éticos, capaz de conhecer e intervir sobre os problemas/situações de saúde-doença, capacitado a atuar, com senso de responsabilidade social e compromisso com a cidadania, como promotor da saúde integral do ser humano ${ }^{16}$.

Essas capacidades podem ser desenvolvidas através das metodologias inovadoras, que colocam o graduando como protagonista do seu próprio saber, facilitando a aquisição do conhecimento de forma gradativa, e o tornando crítico criativo. Foram destacados três tipos: PBL, Métodos de caso e Simulações, estas podem ser complementares com as aulas expositivas ou substituídas por ela em um assunto específico.

Essas metodologias ativas não contribuem somente para o crescimento e processo de amadurecimento do graduando. Contribui para mostrar a suas capacidades de aquisição de conhecimento, sua agilidade de colocá-la em prática em campos de estágio, com também para mostrar ao preceptor o quanto esse aluno já conseguiu absorver e correlacionar conteúdos.

A sua eficácia é destacada por ter o professor como mediador facilitador desse processo de aprendizagem não mais como centro do conhecimento. Estas metodologias treinam e orientam o aluno para assumir uma postura ativa no cuidar sendo centro da sua ação. E essa posição como centro da sua ação na assistência prestada, aliado com o conhecimento e autonomia é o que se tem estimado no perfil do enfermeiro nas unidades de emergências hospitalares.

Ficou evidente que no objetivo das metodologias ativas, são contribuir para melhor aproveitamento dos os estágios curriculares, propondo a formação e atuação profissional. Ocorre a integração das habilidades já adquiridas com novos conhecimentos a serem explorados, tornando-os mais confiantes e autônomos da sua prática curricular influenciando e contribuindo também para o grau de satisfação de mais uma etapa a ser cumprida na graduação.

\section{Referências}

1. BRASIL. Ministério da Educação. Base Nacional Comum Curricular. 2015. [Citado 2017 Maio 26]. Disponível em: http://basenacionalcomum.mec.gov.br/\#/site/ini cio

2. ORTEGA MCB, CECAGNO D, SEVA AM, 
SIQUEIRA HCH, LÓPEZ MJ, MACIÁ L. Formação acadêmica do profissional de enfermagem e sua adequação às atividades de trabalho. Revista Latino-Americana de Enfermagem maio-jun. 2015;23(3):404-10.

3. GONZÁLEZ-CHORDÁ VM, MACIÁ-SOLER ML. Avaliação da qualidade do processo ensinoaprendizagem no curso de graduação em Enfermagem. Revista Latino-Americana de Enfermagem. São Paulo. 2015; 23(4): 700-707.

4. OLIVEIRA LB, MELO VFA, ROUILLER APT, COSTA NF, CARNEIRO TAB. Estratégias de avaliação da aprendizagem Aplicadas no ensino de graduação em enfermagem no Brasil. Revista Iberoamericana de Educación e Investigación en Enfermeira. Argentina. 2015; 5 (1): 57-62.

5. ERCOLE FF, MELO LS, ALCOFORADO CLGC. Revisão integrativa versus revisão sistemática. Reme. 2014; 18(1):9-12.

6. FREIRE AB, FERNANDES DL, MORO JS, KNEIPP MM, CARDOSO CM, et al. Serviços de urgência e emergência: quais os motivos que levam o usuário aos pronto-atendimentos? Saúde. Santa Maria. 2015; 41(1): 195-200.

7. BRASIL. Portaria $n^{\circ} 354$ de 10 de Março de 2014. Pública a proposta de projeto de resolução "boas práticas para organização e funcionamento de serviços de urgência e emergência". Diário oficial da União, 2014.

8. SANTOS JLG, LIMA MADS, PESTANA AL, GARLET ER, ERDMANN AL. Desafios para a gerência do cuidado em emergência na perspectiva de enfermeiro. Acta Paulista de Enfermagem. São Paulo. 2013; 26(2): 136-43.

9. BORGES TS, ALENCAR G. Metodologias ativas na promoção da formação crítica do estudante: o uso das metodologias ativas como recurso didático na formação crítica do estudante do ensino superior. Cairu em Revista. Salvador. 2014; 3(4): 119-143.

10. ROCHA HM, LEMOS WM. Metodologias ativas: do que estamos falando? Base conceitual e relato de pesquisa em andamento. In: IX SIMPED - Simpósio Pedagógico e Pesquisas em Educação; 2014; Rio de Janeiro: Associação Educacional Dom Bosco.

11. XAVIER LN, OLIVEIRA GL, GOMES AA, MACHADO MFAS, ELOIA SMC. Analisando as metodologias ativas na formação dos profissionais de saúde: uma revisão integrativa. Revista de Políticas Públicas. Ceará. 2014; 13(1): 76-83.

12. ROSA RS, SANCHES GJC, GOMES ICR, SILVA MM, DUARTE ACS, BOERY RNSO. Estratégias baseadas em metodologias ativas no ensino aprendizagem de primeiros socorros: relato de experiência. Revista de Enfermagem.
Recife. 2017; 11(2): 798-803.

13. ALVES EATD, COGO ALP. Percepção de estudantes de enfermagem sobre o processo de aprendizagem em ambiente hospitalar. Revista Gaúcha de Enfermagem. 2014 mar; 35(1):102109.

14. HIRSCH CD, BARLEM EL, BARLEM JG, SILVEIRA RS, MENDES DP. Fatores preditores e associados à satisfação dos estudantes de enfermagem. Acta Paulista de Enfermagem. São Paulo. 2015; 6(28): 566-72.

15. WINTERS JRF, DO PRADO ML. Processo de formação crítico-criativo: Percepção dos formandos de enfermagem. Revista iberoamericana de educación e investigación en enfermeria. Argentina. 2015; v.5, n.2, p.17-24.

16. DIRETRIZ Curricular Nacional de Enfermagem, 2014. [Citado 2017 Maio 26]. Disponível em: http://portal.mec.gov.br/cne/arquivos/pdf/Enf.p df

17. BONMANN, D. M. S., COGO, A. L. P. Primeira prática curricular hospitalar de estudantes de Enfermagem descrita em fórum online. Ciência, Cuidado e Saúde. Paraná. v. 12, n. 2, p. 226-232, 2013.

\section{Endereço para Correspondência}

Universidade Estadual do Sudoeste da Bahia UESB

Av. José Moreira Sobrinho $\mathrm{s} / \mathrm{n}$ - Jequiezinho

Jequié (BA)

e-mail: gislene.sanches@hotmail.com

Recebido em 30/10/2019

Aprovado em 28/02/2021

Publicado em 10/05/2021 